\title{
The association between glucose metabolism status, diabetes severity and a history of fractures and recent falls in participants of 50 years and older - the Maastricht Study
}

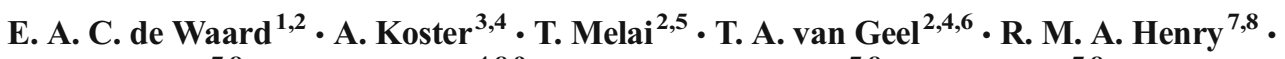 \\ M. T. Schram ${ }^{7,8}$ - P. C. Dagnelie ${ }^{4,8,9}$ - C. J. van der Kallen ${ }^{7,8}$ • S. J. S. Sep ${ }^{7,8}$ • \\ C. D. A. Stehouwer ${ }^{7,8}$ - N. C. Schaper ${ }^{4,7,8}$ - S. Köhler ${ }^{10,11}$ - H. H. C. M. Savelberg ${ }^{2,5}$ • \\ P. P. M. M. Geusens ${ }^{4,12,13}$ • J. P. W. van den Bergh ${ }^{2,12,14}$
}

Received: 11 March 2016 / Accepted: 17 May 2016/Published online: 27 May 2016

(C) The Author(s) 2016. This article is published with open access at Springerlink.com

\begin{abstract}
Summary In this cohort of relatively young and well-treated participants with type 2 diabetes, we found no association between diabetes status and a history of previous fractures and recent falls. Furthermore, no association between diabetes severity and previous fractures or recent falls was found.

Introduction In this study, we examined the association between glucose metabolism status and historical fractures or recent falls and the effect of diabetes severity (glucose control, insulin use, and diabetes duration) on falls and fractures in the participants with type 2 diabetes.

Methods Cross-sectional data from 2005 participants of the Maastricht Study. Falls in the past 6 months and fractures $\geq$ age 50 were assessed by questionnaire. Glucose metabolism status (normal glucose metabolism, impaired glucose metab-
\end{abstract}

E. A. C. de Waard

e.dewaard@maastrichtuniversity.nl

1 Department of Internal Medicine, Subdivision of Rheumatology, Maastricht University, Maastricht, The Netherlands

2 NUTRIM School for Nutrition and Translational Research in Metabolism, Maastricht University, Universiteitssingel 40, room C5.535, P.O. Box 5800, 6202 AZ Maastricht, The Netherlands

3 Department of Social Medicine, Maastricht University, Maastricht, The Netherlands

4 CAPHRI School for Public Health and Primary Care, Maastricht University, Maastricht, The Netherlands

5 Department of Human Movement Sciences, Maastricht University, Maastricht, The Netherlands

6 Department of Family Medicine, Maastricht University, Maastricht, The Netherlands olism, or type 2 diabetes) was based on the oral glucose tolerance test and medication use.

Results In the completely adjusted model, the odds for a fall were not significantly higher in those with impaired glucose metabolism status (OR (95\%CI) 1.28 (0.93-1.77)) or with type 2 diabetes (OR (95\%CI) $1.21(0.80-1.81))$ compared with the group with normal glucose metabolism. Within the group with type 2 diabetes, there were no significant differences with regard to reported falls between participants with HbAlc $>7 \%(53 \mathrm{mmol} / \mathrm{mol})$ versus $\mathrm{HbA} 1 \mathrm{c} \leq 7 \%$ (OR (95\%CI) $1.05(0.58-1.90))$, insulin users versus non-insulin users (OR (95\%CI) $1.51(0.79-2.89))$, and with a diabetes duration $>5$ versus $\leq 5$ years $(\mathrm{OR}(95 \% \mathrm{CI}) 0.52(0.46-1.47)$ ). Similarly, neither glucose metabolism status nor diabetes severity was associated with prior fractures.
7 Department of Internal Medicine, Maastricht University Medical Center, Maastricht, The Netherlands

8 CARIM School for Cardiovascular diseases, Maastricht University, Maastricht, The Netherlands

9 Department of Epidemiology, Maastricht University, Maastricht, The Netherlands

10 MHeNs School for Mental Health and Neuroscience, Maastricht University, Maastricht, The Netherlands

11 Department of Psychiatry and Neurophysiology, Maastricht University, Maastricht, The Netherlands

12 Department of Internal Medicine, Subdivision of Rheumatology, Maastricht University Medical Centre, Maastricht, The Netherlands

13 Biomedical Research Institute, University of Hasselt, Hasselt, Belgium

14 Department of Internal Medicine, Subdivision of Endocrinology, VieCuri Medical Center, Venlo, The Netherlands 
Conclusions Glucose metabolism status was not significantly associated with previous fractures and recent falls. In addition, in this cohort of relatively young and well-treated participants with type 2 diabetes, diabetes severity was not associated with previous fractures and recent falls.

Keywords Diabetes severity $\cdot$ Falls $\cdot$ Fractures $\cdot$ Type 2 diabetes mellitus

\section{Introduction}

Falls are a major public health problem that causes considerable morbidity and affects the quality of life of people around the world [1]. Several risk factors for falls, such as age, physical inactivity, loss of balance, and loss of vision, have been identified. Due to both complications of their disease and a direct effect of the disease on bone quality, patients with type 2 diabetes are thought to have an increased fall and fracture risk $[2,3]$. However, conflicting results about fall and fracture risk in patients with type 2 diabetes have been described. Compared to subjects with normal glucose metabolism, fall and fracture risk may be either comparable or increased in patients with type 2 diabetes [3-10]. These different results may be explained by differences in the way diabetes has been diagnosed (self-reported vs. an oral glucose tolerance test (OGTT) ) and how falls and fractures have been reported (retrospective vs. prospective). Furthermore, indicators of diabetes severity such as the degree of glucose control, the duration of disease, and the prevalence of insulin use are often not reported. This may have resulted in study populations with different levels of exposure and, consequently, different results $[4,5,7,8,10]$.

Only few studies about fracture risk and no studies about fall risk in people with impaired glucose metabolism (defined as either impaired fasting glucose or impaired glucose tolerance) have been published. People with impaired glucose metabolism are often overweight, which is associated with a decreased fracture risk [11], and have increased serum levels of insulin [12], which stimulates bone formation. It may therefore be hypothesized that people with impaired glucose metabolism have a decreased fracture risk. Previous studies indeed showed a normal to decreased fracture risk in people with impaired glucose metabolism when compared to people with normal glucose metabolism [6, 12, 13].

In the present study, we examined the association between glucose metabolism status and recent falls and previous fractures in a well-characterized cohort of participants from the Maastricht Study aged 50 years and older. Additionally, we examined the association between glucose control, insulin use, diabetes duration, and falls in the past 6 months and fractures at or above the age of 50 . We hypothesized that the prevalence of falls and fractures in participants with impaired glucose metabolism is similar or decreased when compared to participants with normal glucose metabolism and that the prevalence of falls and fractures in participants with type 2 diabetes is increased only in those with inadequately regulated diabetes, insulin users and those with a long duration of the disease.

\section{Methods}

\section{Study population and design}

We used data from the Maastricht Study, an observational prospective population-based cohort study. The rationale and methodology have been described previously [14]. In brief, the study focuses on the etiology, pathophysiology, complications, and comorbidities of type 2 diabetes mellitus and is characterized by an extensive phenotyping approach. Eligible for participation were all home-dwelling individuals aged between 40 and 75 years and living in the southern part of the Netherlands. Participants were recruited through mass media campaigns and from the municipal registries and the regional Diabetes Patient Registry via mailings. Recruitment was stratified according to known type 2 diabetes status, with an oversampling of individuals with type 2 diabetes for reasons of efficiency. The present report includes cross-sectional data from a subset of the first 3451 participants who completed the baseline survey between November 2010 and September 2013. Participants with type 1 diabetes mellitus or another type of diabetes $(n=41)$ were excluded. Participants aged under 50 $(n=457)$ were excluded because one of our main outcome measures is a historical fracture at or above the age of 50 . From the remaining 2953 participants, data on falls in the past 6 months was available in 2688 participants and on fractures at or above the age of 50 in 2463 participants. To examine the association between type 2 diabetes and falls and fractures only in participants who already had diabetes at the date of their fall or fracture, we excluded participants with an unknown duration of diabetes ( $n=243$ for the fall analysis population and $n=209$ for the fracture analysis population) and those with an unknown date of the fracture. For the fall analysis population, we further excluded participants with type 2 diabetes and a diabetes duration less than 1 year $(n=14)$, or missing data on covariates ( $n=426$ ), leaving 2005 participants for the fall analysis population. For the fracture analysis population, we further excluded type participants with type 2 diabetes who reported a fracture before being diagnosed with diabetes $(n=15)$, or missing data on covariates $(n=392)$, leaving 1847 participants for the fracture analysis population (Fig. 1). The examinations of each participant were performed within a time window of 3 months. All participants were ambulatory. The study has been approved by the institutional medical ethical committee (NL31329.068.10) and the Minister of Health, Welfare and 
Fig. 1 Flow chart of patient selection

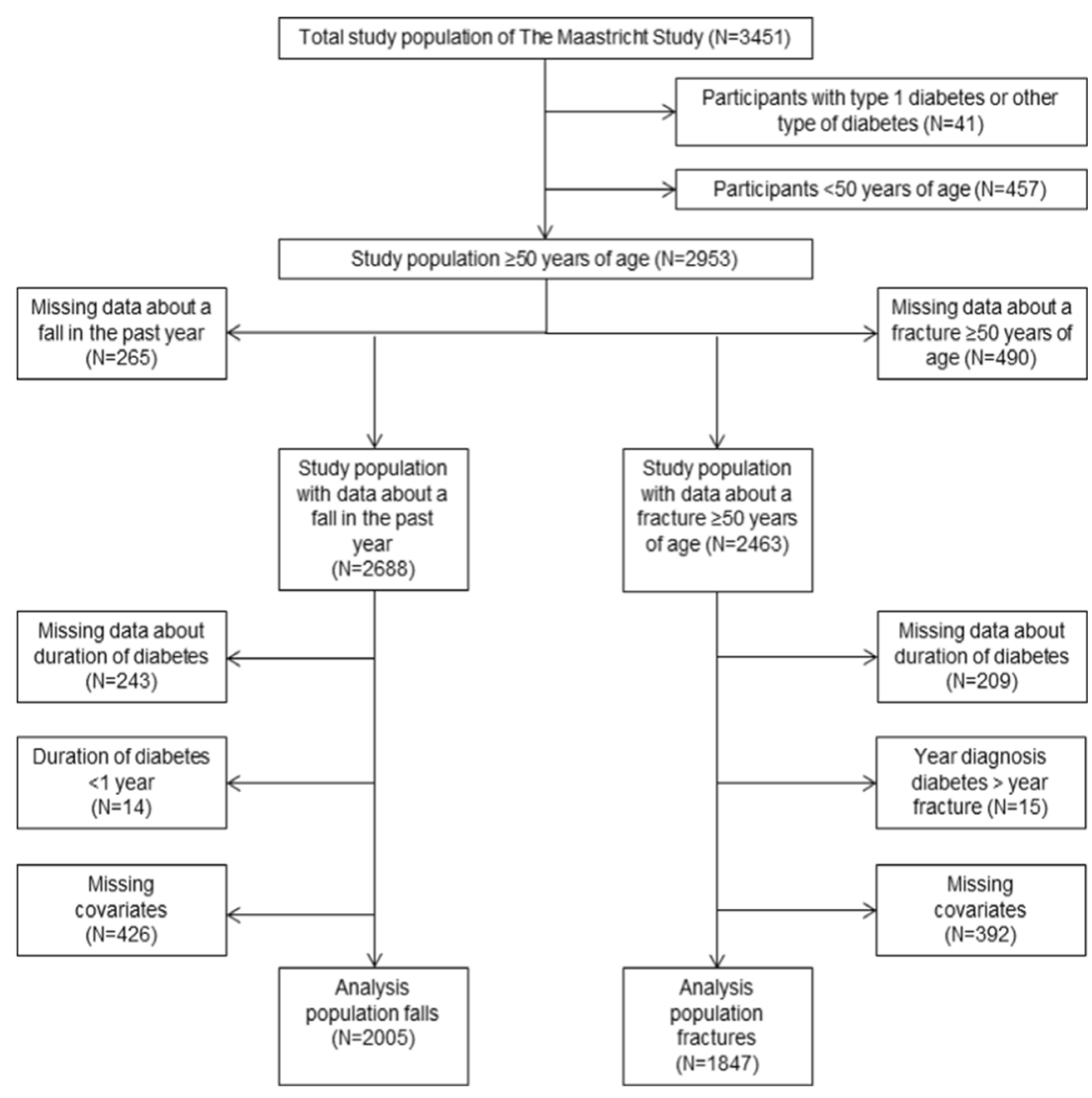

Sports of the Netherlands, on the basis of the Health Council's opinion (Permit 131088-105234-PG). All participants gave written informed consent.

\section{Measures}

\section{Glucose metabolism status}

To determine glucose metabolism status, all participants, except those who used insulin, underwent a standardized 2-h $75 \mathrm{~g}$ OGTT after an overnight fast. For safety reasons, participants with a fasting glucose level $>11.0 \mathrm{mmol} / \mathrm{L}$ (>200.0 mg/ dl), as determined by a capillary blood glucose measurement, did not undergo the OGTT. Fasting glucose level, 2-h plasma glucose level, and information about diabetes medication were used to determine glucose metabolism status. Glucose metabolism was defined according to the WHO 2006 criteria into normal glucose metabolism (fasting plasma glucose $<6.1 \mathrm{mmol} / \mathrm{L}(<110.0 \mathrm{mg} / \mathrm{dl})$ and 2 -h plasma glucose $<7.8 \mathrm{mmol} / \mathrm{L}(<140.0 \mathrm{mg} / \mathrm{dl})$ and no diabetes medication), impaired fasting glucose (fasting plasma glucose 6.1$6.9 \mathrm{mmol} / \mathrm{L}(110.0-125.0 \mathrm{mg} / \mathrm{dl})$ and $2-\mathrm{h}$ plasma glucose $<7.8 \mathrm{mmol} / \mathrm{L}(<140.0 \mathrm{mg} / \mathrm{dl})$ and no diabetes medication), impaired glucose tolerance (fasting plasma glucose $<7.0 \mathrm{mmol} / \mathrm{L}(<126.0 \mathrm{mg} / \mathrm{dl})$ and 2 -h plasma glucose $\geq 7.8$ and $<11.1 \mathrm{mmol} / \mathrm{L}(\geq 140.0$ and $<200.0 \mathrm{mg} / \mathrm{dl})$ and no diabetes medication), and type 2 diabetes (fasting plasma glucose $\geq 7.0 \mathrm{mmol} / \mathrm{L}(\geq 126.0 \mathrm{mg} / \mathrm{dl})$ or 2 -h plasma glucose $\geq 11.1 \mathrm{mmol} / \mathrm{L}$ ( $\geq 200.0 \mathrm{mg} / \mathrm{dl}$ ) or diabetes medication) [15]. Individuals without type 1 diabetes who used diabetes medication were classified as having type 2 diabetes. For this study, we defined having either impaired fasting glucose or impaired glucose tolerance as impaired glucose metabolism. Use of glucose-lowering medication was assessed during a medication interview where generic name, dose, and frequency were registered. Diabetes duration was assessed by questionnaire. HbA1c level was determined as described elsewhere [14].

The group with type 2 diabetes was divided into subgroups of participants with well-regulated disease $(\mathrm{HbA} 1 \mathrm{c} \leq 7 \%$ $(\leq 53 \mathrm{mmol} / \mathrm{mol}))$ and with inadequately regulated disease $(\mathrm{HbAlc}>7 \%(>53 \mathrm{mmol} / \mathrm{mol}))$, in insulin and non-insulin users; and in participants with a diabetes duration $\leq 5$ years and $>5$ years.

\section{Falls and fractures}

Using a web-based questionnaire, participants were asked if they experienced a fall in the past 6 months, and, if so, how many times they fell in the past 6 months. Participants who fell two or more times in the past 6 months were labeled as recurrent fallers. Additionally, participants were asked if they had ever had a fracture and, if so, which bone(s) and the date(s) of 
the fracture(s). A fall in the past 6 months and a fracture at or above the age of 50 were our primary end points.

\section{Covariates}

The following covariates were included: age, sex, educational level, BMI, moderate-to-vigorous physical activity (MVPA), history of cardiovascular disease (CVD), smoking status, alcohol use, use of blood pressure lowering medication, use of lipid-modifying medication, use of benzodiazepines, depression, and cognitive performance.

Level of education was assessed by questionnaire and classified into three categories: low (no education; primary education; or lower vocational education), intermediate (intermediate general secondary education; intermediate vocational education; or higher general secondary education), and high (higher vocational education; or university).

Weight and height were measured without shoes and wearing light clothing using a scale and stadiometer to the nearest $0.5 \mathrm{~kg}$ or $0.1 \mathrm{~cm}$ (Seca, Hamburg, Germany). BMI was calculated by dividing the weight in kilogram by the height in centimeters squared.

MVPA, in hours per week, was calculated from the modified Community Health Activities Model Program for Seniors (CHAMPS) questionnaire [16]. Activities accounted as MVPA were fast walking, fast cycling, heavy gardening, heavy household work, jogging/running, swimming, tennis, team sport, and intensive exercise.

History of CVD, smoking behavior, and alcohol consumption were assessed by questionnaire. Participants were regarded as having a history of CVD if they reported to have had a myocardial infarction and/or cerebrovascular infarction or hemorrhage, and/or percutaneous artery angioplasty or vascular surgery on the coronary, abdominal, peripheral or carotid arteries. Smoking behavior was classified as never, former, and current.

Alcohol consumption was classified into three categories: non-consumers, low consumers $(\leq 7$ glasses per week for women and $\leq 14$ glasses per week for men), and high consumers ( $>7$ glasses per week for women and $>14$ glasses per week for men).

Use of blood pressure lowering medication, lipidmodifying medication, and sleep medication was assessed during a medication interview where generic name, dose, and frequency were registered.

Presence of a depressive disorder in the preceding 2 weeks was assessed by the Mini International Neuropsychiatric Interview according to the Diagnostic and Statistical Manual of Mental Disorders, Fourth Edition (DSM-IV), as described in detail elsewhere [17].

General cognitive performance was assessed using the Minimal Mental State Examination (MMSE) [18]. The examination resulted in a score between 0 and 30, with a score of 24 or less being labeled as impaired cognitive function.
Statistical analysis

All statistical analyses were performed using the Statistical Package for Social Sciences (version 22.0; IBM, Chicago, IL, USA). General characteristics of the study population were compared between the group with normal glucose metabolism, the group with impaired glucose metabolism, and the group with type 2 diabetes. One-way ANOVA was used to test for significant differences of continuous variables and a chi-square test for differences in categorical variables between the normal glucose metabolism, the impaired glucose metabolism, and the type 2 diabetes groups. To examine the association between glucose metabolism status and falls or fractures, and to examine the association between diabetes regulation, insulin use, or duration of diabetes and falls or fractures, logistic regression analysis was used, yielding odds ratios (OR) and $95 \%$ confidence intervals (CI). The same models were used for all regression analyses; model 1 was an unadjusted model; model 2 included age, sex, and level of education; and model 3 was additionally adjusted for BMI, MVPA, a history of CVD, smoking status, alcohol consumption, the use of blood pressure lowering medication, the use of lipidmodifying drugs, the use of sleep medication, depression, and cognitive function. A $p$ value less than 0.05 was considered statistically significant. In additional analyses, the association between glucose metabolism status and recurrent falls was examined, using multinomial logistic regression analysis. Interactions of sex of the participant with the respective exposure variables of interest (i.e., glucose metabolism status, diabetes regulation, insulin use, or duration of diabetes) were tested for all regression analyses.

\section{Results}

General characteristics of the fall analysis population according to glucose metabolism status are shown in Table 1. In total, 1246 participants were classified as having normal glucose metabolism, 359 as having impaired glucose metabolism, and 400 as having type 2 diabetes. Participants with type 2 diabetes were the oldest, the least likely to be female, had the lowest level of education, the highest BMI, and the highest prevalence of depression. Participants with normal glucose metabolism had the lowest prevalence of CVD and the highest prevalence of non-smokers. Alcohol consumption was the lowest in the group with type 2 diabetes. The mean $\mathrm{HbA} 1 \mathrm{c}$ level of the group with type 2 diabetes was $7.0 \%(53.4 \mathrm{mmol} /$ mol); almost $93 \%$ used antidiabetic drugs, including insulin in $26 \%$. The median diabetes duration was 7.0 years. The prevalence of a fall in the past 6 months and the number of falls in the past 6 months was not significantly different between the groups, while the prevalence of a fracture at or above the age of 50 was lowest in the group with type 2 
Table 1 General characteristics of the study population by glucose metabolism status

\begin{tabular}{|c|c|c|c|c|}
\hline & $\begin{array}{l}\text { NGM } \\
(n=1246)\end{array}$ & $\begin{array}{l}\text { IGM } \\
(n=359)\end{array}$ & $\begin{array}{l}\text { T2DM } \\
(n=400)\end{array}$ & $p$ value \\
\hline Age (years) & $60.5(6.1)$ & $63.0(5.9)$ & $63.4(6.3)$ & $<0.001$ \\
\hline Female sex & $708(56.8)$ & $158(44.0)$ & $128(32.0)$ & $<0.001$ \\
\hline \multicolumn{5}{|l|}{ Level of education } \\
\hline - Low & $344(27.6)$ & $131(36.5)$ & $165(41.3)$ & \multirow[t]{3}{*}{$<0.001$} \\
\hline - Medium & $324(26.0)$ & $92(25.6)$ & $124(31.0)$ & \\
\hline - High & $578(46.4)$ & $136(37.9)$ & $111(27.8)$ & \\
\hline BMI $\left(\mathrm{kg} / \mathrm{m}^{2}\right)$ & $25.5(3.6)$ & $27.9(4.2)$ & $29.7(4.7)$ & $<0.001$ \\
\hline Self-reported MVPA (hours/week) & $6.2(4.5)$ & $5.2(4.2)$ & $4.4(4.1)$ & $<0.001$ \\
\hline History of CVD & $154(12.4)$ & $50(13.9)$ & $120(30.0)$ & $<0.001$ \\
\hline \multicolumn{5}{|l|}{ Smoking status } \\
\hline - Never & $471(37.8)$ & $103(28.7)$ & $109(27.3)$ & \multirow[t]{3}{*}{$<0.001$} \\
\hline - Former & $645(51.8)$ & $219(61.0)$ & $241(60.3)$ & \\
\hline - Current & $130(10.4)$ & $37(10.3)$ & $50(12.5)$ & \\
\hline \multicolumn{5}{|l|}{ Alcohol consumption category } \\
\hline - None & $142(11.4)$ & $52(14.5)$ & $114(28.5)$ & \multirow[t]{3}{*}{$<0.001$} \\
\hline - Low & $715(57.4)$ & $194(54.0)$ & $217(54.3)$ & \\
\hline - High & $389(31.2)$ & $113(31.5)$ & $69(17.3)$ & \\
\hline \multicolumn{5}{|l|}{ Medication use } \\
\hline - Antidiabetic drugs & - & - & $371(92.8)$ & - \\
\hline - Insulin & - & - & $104(26.0)$ & - \\
\hline - Blood pressure lowering drugs & $303(24.3)$ & $168(46.8)$ & $296(74.0)$ & $<0.001$ \\
\hline - Lipid-modifying drugs & $237(19.0)$ & $135(37.6)$ & $315(78.8)$ & $<0.001$ \\
\hline - Sleep medication & $27(2.2)$ & $11(3.1)$ & $9(2.3)$ & 0.61 \\
\hline Depression & $21(1.7)$ & $9(2.5)$ & $20(5.0)$ & 0.001 \\
\hline MMSE score & $29.2(1.1)$ & $28.9(1.2)$ & $28.7(1.4)$ & $<0.001$ \\
\hline HbAlc $(\%)$ & $5.5(0.3)$ & $5.7(0.4)$ & $7.0(1.1)$ & $<0.001$ \\
\hline $\mathrm{HbA1c}(\mathrm{mmol} / \mathrm{mol})$ & $36.4(3.7)$ & $39.0(4.4)$ & $53.4(11.5)$ & $<0.001$ \\
\hline Duration of diabetes in years, mean (IQR) & - & - & $7.0(9.0)$ & - \\
\hline Fall in the past 6 months & $204(16.4)$ & $72(20.1)$ & $66(16.5)$ & 0.25 \\
\hline \multicolumn{5}{|l|}{ Number of falls in the past 6 months } \\
\hline-0 & $1042(83.6)$ & $287(79.9)$ & $334(83.5)$ & \multirow[t]{3}{*}{0.44} \\
\hline-1 & $134(10.8)$ & $51(14.2)$ & $42(10.5)$ & \\
\hline$-\geq 2$ & $70(5.6)$ & $21(5.8)$ & $24(6.0)$ & \\
\hline Fracture $\geq 50$ years of age & $119(10.3)$ & $40(12.3)$ & $19(5.4)$ & 0.006 \\
\hline
\end{tabular}

Continues variables are presented as mean (SD) unless otherwise stated, categorical variables as number of participants (\%)

$B M I$ body mass index, $C V D$ cardiovascular disease, $I G M$ impaired glucose metabolism, $I Q R$ Interquartile range MVPA moderate-to-vigorous physical activity, $N G M$ normal glucose metabolism, $S D$ standard deviation, $T 2 D M$ type 2 diabetes diabetes. The general characteristics of the fracture analysis population according to glucose metabolism status were comparable to those of the fall analysis population (not tabulated).

Table 2 shows the association between glucose metabolism status and falls or fractures. The odds ratio (OR) for a fall was significantly increased in participants with impaired glucose metabolism (OR (95\% CI) 1.37 (1.01-1.87)) after adjustment for age, sex, and level of education (model 2). After further adjustment (model 3) the OR was no longer statistically significant (OR (95\% CI) $1.28(0.93-1.77)$ ). The addition of $\mathrm{BMI}$ to model 2 resulted in loss of statistical significance (data not shown). When the impaired glucose metabolism group was divided into participants with impaired fasting glucose and in participants with impaired glucose tolerance, the odds for a fall was increased only in participants with impaired glucose tolerance after adjustment for age, sex, and level of education (model 2, OR (95\% CI) 1.42 (1.01-1.99)). The odds for a fall in the group with type 2 diabetes was not 
Table 2 The association between glucose metabolism status and falls in the past 6 months or fractures at or above the age of 50

\begin{tabular}{clllll}
\hline & $\begin{array}{l}\text { Number of falls/ } \\
\text { fractures }\end{array}$ & $\begin{array}{l}\text { Number of } \\
\text { participants }\end{array}$ & $\begin{array}{l}\text { Model 1 } \\
\text { OR } \\
(95 \% \text { CI })\end{array}$ & $\begin{array}{l}\text { Model 2 } \\
\text { OR } \\
(95 \% \text { CI })\end{array}$ & $\begin{array}{l}\text { Model 3 } \\
\text { OR } \\
(95 \% \text { CI })\end{array}$ \\
\hline Falls & & & & Ref \\
NGM & 204 & 1246 & Ref & Ref & $1.28(0.93-1.77)$ \\
IGM & 72 & 359 & $1.28(0.95-1.73)$ & $1.37(1.01-1.87)$ & $1.16(0.65-2.07)$ \\
- IFG & 16 & 93 & $1.06(0.61-1.86)$ & $1.25(0.71-2.20)$ & $1.32(0.93-1.89)$ \\
- IGT & 56 & 266 & $1.36(0.98-1.90)$ & $1.42(1.01-1.99)$ & $1.95(0.64-1.40)$ \\
T2DM & 66 & 400 & $1.01(0.75-1.37)$ & $1.17(0.85-1.62)$ & 0.95 \\
Fractures & & & & & Ref \\
NGM & 119 & 1162 & Ref & $1.20(0.80-1.78)$ & $1.28(0.84-1.95)$ \\
IGM & 40 & 326 & $1.23(0.84-1.80)$ & $1.24(0.59-2.58)$ & $1.30(0.62-2.76)$ \\
- IFG & 9 & 85 & $1.04(0.51-2.13)$ & $1.19(0.76-1.85)$ & $1.28(0.81-2.02)$ \\
- IGT & 31 & 241 & $1.29(0.85-1.97)$ & $0.55(0.32-0.92)$ & $0.70(0.38-1.27)$ \\
T2DM & 19 & 359 & $0.49(0.30-0.81)$ & & \\
\hline
\end{tabular}

Model 1: unadjusted, model 2: adjusted for age, sex, and level of education, model 3: model 2 + BMI, MVPA, a history of CVD, smoking status, alcohol consumption, the use of blood pressure lowering drugs, the use of lipidmodifying drugs, the use of sleep medication, depression, and cognitive function. NGM is the reference category $C I$ confidence interval, IGM impaired glucose metabolism, $N G M$ normal glucose metabolism, $O R$ odds ratio, T2DM type 2 diabetes mellitus

Statistically significant results are presented in italic statistically significantly different from those with a normal glucose metabolism in all models.

The odds for a fracture in the group with impaired glucose metabolism were not statistically significantly different from those with a normal glucose metabolism in all models. The odds for a fracture were significantly decreased in participants with type 2 diabetes after adjustment for age, sex, and level of education (model 2, OR (95\% CI) $0.55(0.32-0.92)$ ), when compared to participants with normal glucose metabolism. The association was not significantly different anymore after further adjustment for BMI, MVPA, a history of CVD, smoking status, alcohol consumption, the use of blood pressure lowering drugs, lipid-modifying drugs, and sleep medication, and depression and cognitive function (model 3, OR (95\% CI) $0.70(0.38-1.27)$ ).

Table 3 shows the association between diabetes regulation, insulin use, or diabetes duration and falls or fractures in the group with type 2 diabetes. The mean HbA1c level of the subgroup with an $\mathrm{HbA1c}>7 \%$ (>53 $\mathrm{mmol} / \mathrm{mol})$ was 8.0 $\pm 1.0 \%(64.4 \pm 11.4 \mathrm{mmol} / \mathrm{mol})$; the mean $\mathrm{HbAlc}$ level of the subgroup with an $\mathrm{HbAlc} \leq 7 \%(\leq 53 \mathrm{mmol} / \mathrm{mol})$ was $6.4 \pm 0.4 \%(46.9 \pm 4.3 \mathrm{mmol} / \mathrm{mol})$. The median duration of diabetes of the subgroup with a diabetes duration $>5$ years was 11.0 (interquartile range (IQR) 8.0) years, and of the subgroup with a diabetes duration $\leq 5$ years was 3.0 (IQR 2.0) years. The OR for a fall of participants with an HbA1c $>7 \%(53 \mathrm{mmol} / \mathrm{mol})$, insulin users, or participants with a diabetes duration of more than 5 years was not statistically significantly different from those of participants with an HbAlc $\leq 7 \%$ (53 mmol $/ \mathrm{mol})$, non-insulin users, and those with a duration of 5 years or less, respectively, in all the models. Similarly, there were no statistically significant associations between $\mathrm{HbA} 1 \mathrm{c}$, insulin use, or diabetes duration and fractures.

In additional analyses, we examined the association between glucose metabolism status and recurrent falls (data not tabulated). Impaired glucose metabolism and type 2 diabetes were not statistically significantly associated with recurrent falls. Finally, the results of the regression analyses for a fall in the past 6 months or recurrent falls in the past 6 months were similar to those described above, when the fracture analysis population instead of the fall analysis population was used.

\section{Discussion}

In this study, we examined the association between glucose metabolism status and a history of fractures and recent falls in a group of 2005 participants at or above the age of 50 from the Maastricht Study. In contrast to our hypothesis, we did not find a significant association between glucose metabolism status and a history of falls or fractures. Diabetes severity, in terms of inadequately regulated disease, insulin use, or duration of diabetes, was also not significantly associated with increased odds of prior fractures or recent falls. 
Table 3 The association between diabetes regulation, insulin use, or duration of diabetes and falls or fractures

\begin{tabular}{|c|c|c|c|c|c|}
\hline & $\begin{array}{l}\text { Number of falls/ } \\
\text { fractures }\end{array}$ & $\begin{array}{l}\text { Number of } \\
\text { participants }\end{array}$ & $\begin{array}{l}\text { Model } 1 \\
\text { OR } \\
(95 \% \mathrm{CI})\end{array}$ & $\begin{array}{l}\text { Model } 2 \\
\text { OR } \\
(95 \% \mathrm{CI})\end{array}$ & $\begin{array}{l}\text { Model } 3 \\
\text { OR } \\
(95 \% \mathrm{CI})\end{array}$ \\
\hline \multicolumn{6}{|l|}{ Falls } \\
\hline $\begin{array}{c}\mathrm{HbAlc} \leq 7 \% \\
\mathrm{mmol} / \mathrm{mol})\end{array}$ & 41 & 250 & Ref & Ref & Ref \\
\hline $\begin{array}{c}\mathrm{HbAlc}>7 \%(53 \\
\mathrm{mmol} / \mathrm{mol})\end{array}$ & 25 & 150 & $\begin{array}{l}1.02 \\
(0.59-1.76)\end{array}$ & $\begin{array}{l}1.09 \\
(0.62-1.92)\end{array}$ & $\begin{array}{l}1.05 \\
(0.58-1.90)\end{array}$ \\
\hline Insulin - & 44 & 296 & Ref & Ref & Ref \\
\hline Insulin + & 22 & 104 & $\begin{array}{l}1.54 \\
(0.87-2.72)\end{array}$ & $\begin{array}{l}1.63 \\
(0.90-2.94)\end{array}$ & $\begin{array}{l}1.51 \\
(0.79-2.89)\end{array}$ \\
\hline $\begin{array}{l}\text { Diabetes duration } \\
\leq 5 \text { years }\end{array}$ & 30 & 173 & Ref & Ref & Ref \\
\hline $\begin{array}{l}\text { Diabetes duration } \\
>5 \text { years }\end{array}$ & 36 & 227 & $\begin{array}{l}0.90 \\
(0.53-1.53)\end{array}$ & $\begin{array}{l}0.86 \\
(0.50-1.49)\end{array}$ & $\begin{array}{l}0.83 \\
(0.46-1.47)\end{array}$ \\
\hline \multicolumn{6}{|l|}{ Fractures } \\
\hline $\begin{array}{l}\mathrm{HbA} 1 \mathrm{c} \leq 7 \% \\
\quad(53 \mathrm{mmol} / \mathrm{mol})\end{array}$ & 13 & 225 & Ref & Ref & Ref \\
\hline $\begin{array}{l}\mathrm{HbA} 1 \mathrm{c}>7 \% \\
\quad(53 \mathrm{mmol} / \mathrm{mol})\end{array}$ & 6 & 134 & $\begin{array}{l}0.76 \\
(0.28-2.06)\end{array}$ & $\begin{array}{l}0.69 \\
(0.25-1.90)\end{array}$ & $\begin{array}{l}0.53 \\
(0.18-1.59)\end{array}$ \\
\hline Insulin - & 13 & 269 & Ref & Ref & Ref \\
\hline Insulin + & 6 & 90 & $\begin{array}{l}1.41 \\
(0.52-3.82)\end{array}$ & $\begin{array}{l}1.27 \\
(0.46-3.50)\end{array}$ & $\begin{array}{l}1.39 \\
(0.44-4.33)\end{array}$ \\
\hline $\begin{array}{l}\text { Duration of diabetes } \\
\leq 5 \text { years }\end{array}$ & 11 & 158 & Ref & Ref & Ref \\
\hline $\begin{array}{l}\text { Duration of diabetes } \\
>5 \text { years }\end{array}$ & 8 & 201 & $\begin{array}{l}0.55 \\
(0.22-1.41)\end{array}$ & $\begin{array}{l}0.50 \\
(0.19-1.31)\end{array}$ & $\begin{array}{l}0.52 \\
(0.19-1.44)\end{array}$ \\
\hline
\end{tabular}

Model 1: unadjusted, model 2: adjusted for age, sex, and level of education, model 3: model 2 + BMI, MVPA, a history of CVD, smoking status, alcohol consumption, the use of blood pressure lowering drugs, the use of lipidmodifying drugs, the use of sleep medication, depression, and cognitive function. $\mathrm{HbAlc} \leq 7 \%(53 \mathrm{mmol} / \mathrm{mol})$, insulin, and duration of diabetes $\leq 5$ years are the reference categories

$C I$ confidence interval, $O R$ odds ratio
Previous cross-sectional fall studies showed no significant difference in fall rate between participants with and without type 2 diabetes [9, 19]. However, both studies used a small sample size and only showed results of univariate analyses. The results of previous prospective studies on fall risk in patients with type 2 diabetes are conflicting; some studies showed an increased fall risk [8, 10, $20,21]$, while others showed a fall risk similar to participants without diabetes [7, 13].

Our study is in line with two out of three previous cross-sectional studies that investigated the association between type 2 diabetes and fractures, where significant association between type 2 diabetes and all types of fractures and hip fractures specifically was showed $[4,6]$. Additionally, no association between an impaired fasting glucose and fractures was shown [6]. In contrast, two meta-analyses and a recent large prospective study showed an increased fracture risk in patients with type 2 diabetes [3, 22, 23]. However, none of the prospective fall and fracture studies provided information on $\mathrm{HbAlc}$ levels, the percentage of insulin users, and the duration of diabetes. This lack of information hampers the comparison of these studies, since they may have been conducted in patient populations with different characteristics regarding type 2 diabetes.

In our study, participants with type 2 diabetes had generally well-regulated diabetes (mean $\mathrm{HbAlc}$ level $7.0 \%$ $(53.4 \mathrm{mmol} / \mathrm{mol}))$, a relatively short median duration of the disease ( 7.0 years), and the percentage of insulin users was low $(26.0 \%)$. A potential explanation for the nonsignificant differences in fall and fracture rate between those with and without type 2 diabetes is that an increased fall and fracture risk is only present in patients with more severe and longer duration of the disease. Indeed, several prospective cohort studies showed that only inadequately regulated diabetes was associated with an increased fall and fracture risk $[13,24,25]$. In the current, study we did not find statistically significant differences in the odds of falls and fractures in inadequately versus adequately regulated participants with type 2 diabetes, in those with a 
duration of diabetes $>5$ years versus $\leq 5$ years, nor between insulin users versus non-insulin users. The cut-off values for $\mathrm{HbAlc}$ level and duration of diabetes we chose can be discussed. We used an HbA1c level of $7 \%$ (53 $\mathrm{mmol} / \mathrm{mol}$ ) as cut-off value because this is the target value for diabetes treatment [26]. The mean HbA1c level of our inadequately regulated group was $8.0 \%$ ( $64.4 \mathrm{mmol} / \mathrm{mol})$, which is close to the target value and may explain the absence of the different fall and fracture rates between the group with adequately and inadequately regulated diabetes. Only few patients in our cohort of patients with type 2 diabetes had HbAlc levels above $9 \%$; it was therefore not possible to examine the association between different degrees of glucose metabolism regulation and falls or fractures.

The absolute number of fractures in both of our groups of participants with an impaired glucose metabolism and of participants with type 2 diabetes was very low ( $n=40$ and $n=19$, respectively), which is remarkable given the large number of participants in each group and the fact that quite a high number of participants reported at least one fall in the previous 6 months $(N=66$ and $N=56$, respectively). Due to this low absolute number of total fractures, there may be a power problem for showing an association between glucose metabolism status and fractures.

The meta-analysis by Janghorbani et al. showed an increased hip fracture risk, but no association between type 2 diabetes and fractures of the distal forearm, proximal humerus, or vertebra [22]. In contrast, the meta-analysis by Vestergaard et al. showed an increase in wrist fracture risk, but not in non-vertebral and spine fracture risk [3]. Because of the low absolute number of fractures observed in our study, we were not able to examine specific types of fractures.

To the best of our knowledge, up to this date, no studies have been performed on the association between impaired glucose metabolism and falls. Fracture risk has previously been shown to be normal or decreased in participants with impaired glucose metabolism $[6,12,13]$. Because most fractures occur due to a fall [27], a normal to decreased fall risk may be expected. On the other hand, our participants with impaired glucose metabolism were less physically active than participants with normal glucose metabolism and this may lead to some degree of muscle weakness in participants with impaired glucose metabolism and therefore an increased fall risk. Furthermore, the BMI of our participants with impaired glucose metabolism was significantly higher than the BMI of participants with normal glucose metabolism, which could also contribute to an increased falling frequency [28]. In our study, we found a significant association between impaired glucose metabolism and a fall in the past 6 months after adjustment for demographic factors. The association became non-significant after adjustment for BMI and other confounders, so the increased odds of fall in participants with an impaired glucose metabolism in model 2 may be partly explained by their increased BMI. No statistically significant association between participants with impaired glucose metabolism and fractures was found.

Strengths of this study include the objective determination of the glucose metabolism status in a large study population, the well-characterized study cohort, and the availability of extensive information about our participants with type 2 diabetes. In contrast to many previous studies, glucose metabolism status was determined with an OGTT, which allowed us to compare distinct groups of participants. Information about insulin use, an objectively determined $\mathrm{HbAlc}$ level, and the duration of diabetes was well registered for all participants with type 2 diabetes which enabled us to compare different subgroups of participants with type 2 diabetes.

Limitations of our study include the absence of a definition of 'fall' in our questionnaire, the cross-sectional study design, the use of retrospectively collected and self-reported data on falls and fractures, and the lack of information about complications of diabetes. According to the PROFANE guideline [29], a fall should be defined as "an unexpected event in which the participants come to rest on the ground, floor, or lower level." Due to the absence of this definition, participants may have either reported a fall that did not meet the definition or not reported a fall that did meet the definition. Prospective collection of data on falls using a fall diary and on fractures using radiology rapports is preferable over the use of selfreported falls and fractures. However, previous research showed that the accuracy of both self-reported falls and fractures is reasonable [30-32]. Because data about falls and fractures were collected retrospectively, it is not possible to assess whether participants labeled as having impaired glucose metabolism already had impaired glucose metabolism at the moment of their fall or fracture. Because we wanted to be sure to examine the association between type 2 diabetes and falls and fractures only in participants who already had diabetes at the date of their fall or fracture, we excluded participants with an unknown duration of diabetes and those with an unknown date of the fracture. This may have contributed to the low absolute number of fractures that were left for our analyses. In our study, we used $\mathrm{HbAlc}$ level, insulin use, and diabetes duration instead of complications of diabetes as markers of diabetes severity. Future studies are needed to study the association between complications of diabetes and falls and fractures.

In conclusion, glucose metabolism status was not significantly associated with a history of fractures or recent falls. Furthermore, diabetes severity was also not significantly associated with prior fractures or recent falls. This study suggests that the fall and fracture rate may not be increased in relatively young patients with generally well-regulated type 2 
diabetes. Prospective cohort studies with an extensively described type 2 diabetes cohort should be performed to confirm these results.

Acknowledgments This study was supported by the European Regional Development Fund via OP-Zuid, the Province of Limburg, the Dutch Ministry of Economic Affairs (grant 310.041), Stichting De Weijerhorst (Maastricht, the Netherlands), the Pearl String Initiative Diabetes (Amsterdam, the Netherlands), the Cardiovascular Center (CVC, Maastricht, the Netherlands), Cardiovascular Research Institute Maastricht (CARIM, Maastricht, the Netherlands), School for Public Health and Primary Care (CAPHRI, Maastricht, the Netherlands), School for Nutrition, Toxicology and Metabolism (NUTRIM, Maastricht, the Netherlands), Stichting Annadal (Maastricht, the Netherlands), Health Foundation Limburg (Maastricht, the Netherlands), and by unrestricted grants from Janssen-Cilag B.V. (Tilburg, the Netherlands), Novo Nordisk Farma B.V. (Alphen aan den Rijn, the Netherlands), and Sanofi-Aventis Netherlands B.V. (Gouda, the Netherlands)

Compliance with ethical standards The study has been approved by the institutional medical ethical committee (NL31329.068.10) and the Minister of Health, Welfare and Sports of the Netherlands, on the basis of the Health Council's opinion (Permit 131088-105234-PG). All participants gave written informed consent.

\section{Conflict of interest None.}

Open Access This article is distributed under the terms of the Creative Commons Attribution-NonCommercial 4.0 International License (http:// creativecommons.org/licenses/by-nc/4.0/), which permits any noncommercial use, distribution, and reproduction in any medium, provided you give appropriate credit to the original author(s) and the source, provide a link to the Creative Commons license, and indicate if changes were made.

\section{References}

1. World Health Organization (2012) Fact sheet falls. http://www. who.int/mediacentre/factsheets/fs $344 / \mathrm{en} /$

2. de Waard EA, van Geel TA, Savelberg HH, Koster A, Geusens PP, van den Bergh JP (2014) Increased fracture risk in patients with type 2 diabetes mellitus: an overview of the underlying mechanisms and the usefulness of imaging modalities and fracture risk assessment tools. Maturitas 79:265-274. doi:10.1016/j.maturitas.2014. 08.003

3. Vestergaard P (2007) Discrepancies in bone mineral density and fracture risk in patients with type 1 and type 2 diabetes - a metaanalysis. Osteoporos lnt 18:427-444. doi:10.1007/s00198-0060253-4

4. Hothersall EJ, Livingstone SJ, Looker HC, Ahmed SF, Cleland S, Leese GP et al (2014) Contemporary risk of hip fracture in type 1 and type 2 diabetes: a national registry study from Scotland. J Bone Miner Res 29:1054-1060. doi:10.1002/jbmr.2118

5. Carnevale V, Morano S, Fontana A, Annese MA, Fallarino M, Filardi T et al (2014) Assessment of fracture risk by the FRAX algorithm in men and women with and without type 2 diabetes mellitus: a cross-sectional study. Diabetes Metab Res Rev 30: 313-322. doi:10.1002/dmrr.2497

6. Jiajue R, Jiang Y, Wang O, Li M, Xing X, Cui L et al (2014) Suppressed bone turnover was associated with increased osteoporotic fracture risks in non-obese postmenopausal Chinese women with type 2 diabetes mellitus. Osteoporos Int 25:19992005. doi:10.1007/s00198-014-2714-5

7. Pijpers E, Ferreira I, de Jongh RT, Deeg DJ, Lips P, Stehouwer CD et al (2012) Older individuals with diabetes have an increased risk of recurrent falls: analysis of potential mediating factors: the Longitudinal Ageing Study Amsterdam. Age Ageing 41:358365. doi:10.1093/ageing/afr145

8. Maurer MS, Burcham J, Cheng H (2005) Diabetes mellitus is associated with an increased risk of falls in elderly residents of a longterm care facility. J Gerontol A Biol Sci Med Sci 60:1157-1162

9. Bruce D, Hunter M, Peters K, Davis T, Davis W (2015) Fear of falling is common in patients with type 2 diabetes and is associated with increased risk of falls. Age Ageing 44:687-690. doi:10.1093/ ageing/afv024

10. Schwartz AV, Hillier TA, Sellmeyer DE, Resnick HE, Gregg E, Ensrud KE et al (2002) Older women with diabetes have a higher risk of falls: a prospective study. Diabetes Care 25:1749-1754

11. De Laet C, Kanis JA, Oden A, Johanson H, Johnell O, Delmas P et al (2005) Body mass index as a predictor of fracture risk: a metaanalysis. Osteoporos Int 16:1330-1338. doi:10.1007/s00198-0051863-y

12. de Liefde II, van der Klift M, de Laet CE, van Daele PL, Hofman A, Pols HA (2005) Bone mineral density and fracture risk in type-2 diabetes mellitus: the Rotterdam Study. Osteoporos Int 16:17131720. doi:10.1007/s00198-005-1909-1

13. Oei L, Zillikens MC, Dehghan A, Buitendijk GH, CastanoBetancourt MC, Estrada K et al (2013) High bone mineral density and fracture risk in type 2 diabetes as skeletal complications of inadequate glucose control: the Rotterdam Study. Diabetes Care 36:1619-1628. doi:10.2337/dc12-1188

14. Schram MT, Sep SJ, van der Kallen CJ, Dagnelie PC, Koster A, Schaper N et al (2014) The Maastricht Study: an extensive phenotyping study on determinants of type 2 diabetes, its complications and its comorbidities. Eur J Epidemiol 29:439-451. doi:10.1007/ s10654-014-9889-0

15. World Health Organization (2006) Definition and diagnosis of diabetes mellitus and intermediate hyperglycemia: report of a WHO/ IDF consultation. Switzerland, Geneva

16. Stewart AL, Mills KM, King AC, Haskell WL, Gillis D, Ritter PL (2001) CHAMPS physical activity questionnaire for older adults: outcomes for interventions. Med Sci Sport Exerc 33:1126-1141

17. Sheehan DV, Lecrubier Y, Sheehan KH, Amorim P, Janavs J, Weiller E et al (1998) The Mini-International Neuropsychiatric Interview (M.I.N.I.): the development and validation of a structured diagnostic psychiatric interview for DSM-IV and ICD-10. J Clin Psychiatry 59(Suppl 20):22-33, quiz 34-57

18. Folstein MF, Folstein SE, McHugh PR (1975) Mini-mental state. A practical method for grading the cognitive state of patients for the clinician. J Psychiatr Res 12:189-198

19. Oliveira PP, Fachin SM, Tozatti J, Ferreira MC, Marinheiro LP (2012) Comparative analysis of risk for falls in patients with and without type 2 diabetes mellitus. Rev Assoc Med Bras 58:234-239

20. Roman de Mettelinge T, Cambier D, Calders P, Van Den Noortgate N, Delbaere K (2013) Understanding the relationship between type 2 diabetes mellitus and falls in older adults: a prospective cohort study. Plos One 8:e67055. doi:10.1371/journal.pone.0067055

21. Volpato S, Leveille SG, Blaum C, Fried LP, Guralnik JM (2005) Risk factors for falls in older disabled women with diabetes: the women's health and aging study. J Gerontol A Biol Sci Med Sci 60: $1539-1545$

22. Janghorbani M, Van Dam RM, Willett WC, Hu FB (2007) Systematic review of type 1 and type 2 diabetes mellitus and risk of fracture. Am J Epidemiol 166:495-505. doi:10.1093/aje/ kwm106 
23. Bonds DE, Larson JC, Schwartz AV, Strotmeyer ES, Robbins J, Rodriguez BL et al (2006) Risk of fracture in women with type 2 diabetes: the Women's Health Initiative Observational Study. J Clin Endocrinol Metab 91:3404-3410. doi:10.1210/jc.2006-0614

24. Schwartz AV, Vittinghoff E, Sellmeyer DE, Feingold KR, de Rekeneire N, Strotmeyer ES et al (2008) Diabetes-related complications, glycemic control, and falls in older adults. Diabetes Care 31:391-396. doi:10.2337/dc07-1152

25. Li CI, Liu CS, Lin WY, Chen CC, Yang SY, Chen HJ et al (2015) Glycated hemoglobin level and risk of hip fracture in older people with type 2 diabetes: a competing risk analysis of Taiwan Diabetes Cohort Study. J Bone Miner Res 30:1338-1346. doi:10.1002/jbmr.2462

26. Standards of medical care in diabetes - 2015: summary of revisions (2015). Diabetes care 38(Suppl):S4 doi: 10.2337/dc15-S003

27. Nevitt MC (1997) Falls in the elderly: risk factors and prevention. In: Gait disorders of aging: falls and therapeutic strategies. Lippincott-Raven: Philadelphia, pp 13-36

28. Hita-Contreras F, Martinez-Amat A, Lomas-Vega R, Alvarez P, Mendoza N, Romero-Franco N et al (2013) Relationship of body mass index and body fat distribution with postural balance and risk of falls in Spanish postmenopausal women. Menopause 20:202 208. doi:10.1097/gme.0b013e318261f242

29. Lamb SE, Jorstad-Stein EC, Hauer K, Becker C (2005) Development of a common outcome data set for fall injury prevention trials: the Prevention of Falls Network Europe consensus. J Am Geriatr Soc 53:1618-1622. doi:10.1111/j.1532-5415.2005. 53455.x

30. Mackenzie L, Byles J, D'Este C (2006) Validation of selfreported fall events in intervention studies. Clin Rehabil 20: 331-339

31. Ivers RQ, Cumming RG, Mitchell P, Peduto AJ (2002) The accuracy of self-reported fractures in older people. J Clin Epidemiol 55: $452-457$

32. Hundrup YA, Hoidrup S, Obel EB, Rasmussen NK (2004) The validity of self-reported fractures among Danish female nurses: comparison with fractures registered in the Danish National Hospital Register. Scand J Public Health 32:136-143 